\title{
O USO DAS CRIPTOMOEDAS COMO INSTRUMENTO DE SONEGAÇÃO FISCAL: UM ESTUDO SOBRE AS TRANSAÇÕES FINANCEIRAS DE BITCOIN
}

\section{ARTIGO ORIGINAL}

OLIVEIRA, Janayna Mesquita De ${ }^{1}$

RIBEIRO, Marielly Monize Dos Santos ${ }^{2}$

Ó, Marco Aurelio Alves Leal do ${ }^{3}$

ARAÚJO, Jamille Carla Oliveira ${ }^{4}$

OLIVEIRA, Janayna Mesquita De. Et al. 0 uso das criptomoedas como instrumento de sonegação fiscal: um estudo sobre as transações financeiras de bitcoin. Revista Científica Multidisciplinar Núcleo do Conhecimento. Ano 04, Ed. 10, Vol. 07, pp. 05-29. Outubro de 2019. ISSN: 2448-0959, Link de acesso: https://www.nucleodoconhecimento.com.br/contabilidade/uso-das-

\section{criptomoedas}

\section{RESUMO}

No mundo atual onde as inovações em tecnologia digital facilitam a vida das pessoas, as criptomoedas tem ganhado espaço e cada vez mais notoriedade no

1 Discente do curso de Ciências Contábeis da Universidade Federal Rural da Amazônia (UFRA).

2 Discente do curso de Ciências Contábeis da Universidade Federal Rural da Amazônia (UFRA).

3 Doutorando em ciências Contábeis FUCAPE, Mestre em Administração, MBA Gestão contábil, perícia, auditoria e controlaria, Bacharel em Ciências Contábeis.

${ }^{4}$ Mestre em Administração, MBA Gestão contábil, perícia, auditoria e controlaria, Bacharel em Ciências Contábeis. 
mercado. O Objetivo deste trabalho é analisar o uso de criptomoedas como instrumento de sonegação fiscal através de transações financeiras com a moeda virtual Bitcoin, cuja natureza é totalmente descentralizada e não é subserviente a algum tipo de autoridade, o que possibilita as práticas criminosas. (ULRICH,2014). Para isto, foi realizada pesquisa bibliográfica e documental, verificando os registros contábeis do Bitcoin, o uso do mesmo em práticas criminosas e as discussões nacionais e internacionais a respeito da sonegação ou evasão fiscal com criptomoedas. Pretende-se responder às seguintes questões: De que forma as criptomoedas podem ser utilizadas como instrumento de sonegação fiscal através das transações financeiras de bitcoin? Isto é refletido nos registros contábeis? Verificouse que as empresas que aceitam Bitcoin como forma de pagamento, não registram claramente as suas transações com a criptomoeda, nem em notas explicativas são citadas. Como não há uma regulamentação mais específica para essas moedas que circulam no meio virtual, abre-se brechas para que haja a presença da sonegação por parte dos usuários ao declarar o imposto de renda anual bem como em detrimento do ganho de capital em programas disponibilizados pelo endereço eletrônico da Receita Federal Brasileira. Constatou-se ainda que esse problema de sonegação e evasão fiscal através das criptomoedas é global, e vários países estão tomando medidas, regulamentando-as ou proibindo-as, a fim de combater os crimes fiscais e lavagem de dinheiro.

Palavras-chave: Criptomoeda, bitcoin, sonegação fiscal, moeda virtual.

\section{INTRODUÇÃO}

Quando a sociedade evolui, tudo que a integra, acompanham tal evolução. Este pensamento se consolida nas formas de transações comerciais realizadas entre as empresas, destacadamente pela forma como estas empresas realizam as transações financeiras. Desta forma, com a moeda que lastreia estas transações não seria diferente. Devido às dificuldades de realizar transações financeiras no sistema bancário convencional nos diversos centros comerciais e industriais, surgiu, na concepção de Satoshi Nakamoto a ideia de facilitar estas transações criando uma 
moeda virtual, que teria seu lastro baseado na credibilidade dos usuários e na sua influência. (Ulrich, 2014). Assim surgiu o Bitcoin, moeda variável que iremos estudar.

Com a evolução das relações humanas bem como daquelas firmadas no ambiente de trabalho, nosso modo de troca também se desenvolveu. Desde o início das civilizações, muitos modos de troca existiram no mundo. Produtos em excesso da produção, o sal, que deu origem a palavra salário e os metais preciosos (como o ouro e prata) são alguns exemplos de meios que deram vida aos processos de trocas por serviços e bens, que, atualmente, é representado pelas moedas (ROTHBARD, 2014). Cada vez mais a sociedade busca comodidade, praticidade, segurança, agilidade e eficiência nos serviços prestados, e foi com base nessas necessidades da sociedade que está cada vez mais inserida no universo tecnológico, que as criptomoedas foram desenvolvidas. Atualmente, o Bitcoin é a criptomoeda mais utilizada e, por isso, servirá como objeto de estudo para o presente trabalho.

A escolha por esta criptomoeda foi feita por é um mecanismo que possibilita a adesão a bens e a contratação de serviços a partir de taxas menores comparadas com o real, o dólar, e o euro, e vem ganhando grande repercussão mundial (Ulrich, 2014). Para isto, a pesquisa objetiva discorrer sobre o uso de criptomoedas como instrumento de sonegação fiscal através de transações financeiras com a moeda virtual Bitcoin, cuja natureza é totalmente descentralizada e não depende de nenhum tipo de autoridade central, o que possibilita as práticas criminosa. E consequentemente responder a seguinte pergunta problema: o tema sobre Bitcoin ainda tem muito a ser explorado, pois é uma criptomoeda contemporânea com grande possibilidade de se tornar um dos principais meios de trocas nas transações financeiras virtuais, como apontado por Silva (2016).

Ainda que possua uma volatilidade relativamente alta, em comparação às moedas tradicionais, já existe uma grande variedade de empresas que aceitam pagamentos com o Bitcoin, e usuários dispostos a comprarem e venderem este ativo, e apesar de ainda não ser regulamentada no Brasil, suas transações não são proibidas. É com base no poder transformador da tecnologia que o presente trabalho vem analisar como as transações financeiras realizadas com o Bitcoin podem abrir precedentes 
para que os usuários mal-intencionados ocultem transações financeiras no intuito de evitar fiscalização, evadir de obrigações tributárias, e praticar lavagem de dinheiro.

Este estudo, além de ser relevante para a sociedade moderna, por aprimorar o conhecimento a respeito do assunto, deixará uma contribuição acadêmica, servindo de material de apoio aos estudantes e profissionais que exercem ou que pretendem exercer a profissão e conhecer mais do assunto. Diante disso, pretende-se responder a seguinte questão: De que forma as criptomoedas podem ser utilizadas como instrumento de sonegação fiscal por meio das transações realizadas a partir do Bitcoin? Isto é refletido nos registros contábeis? São essas as questões motivadoras do estudo.

\section{REFERENCIAL TEÓRICO}

\subsection{O AMBIENTE DAS CRIPTOMOEDAS}

Antes de discorrer sobre o Bitcoin, no que tange a sua criação, o processo de suas transações e o que determina seu valor de mercado, é necessário compreender como funciona o Blockchain, tecnologia que sob a ótica contábil, seria análogo a um livro razão (CARNUT, 2018). É através dessa plataforma que as transações são efetuadas, validadas e registradas.

\subsubsection{TECNOLOGIA BLOCKCHAIN}

Segundo Diniz (2018), o blockchain é uma ferramenta que tem despertado atenção pois enfatiza uma forma inovadora, com menor custo e segura para o armazenamento de informações. Como uma parcela expressiva das relações sociais e comerciais possui certa dependência aos registros certificados, o blockchain acaba atuando como um instrumento capaz de provocar uma nova revolução tecnológica, visto que, há 20 anos, desde a popularização da internet, tem sido amplamente utilizado nas relações comerciais e sociais. A sua tecnologia pode ser entendida como um sistema que funciona como um banco armazenador de dados que permite a transferência de 
valores e/ou informações sem que tenha que se reportar a uma autoridade central para que essas informações sejam validadas.

A validação, conforme Wosniak e Cerqueira (2017), deve ser feita de maneira compartilhada e descentralizada a partir de uma rede denominada de ponto a ponto que permite que as transações financeiras sejam realizadas de uma parte para outra sem a intermediação de um terceiro. Assim sendo, para Carnut (2018), o blockchain deve ser compreendido como um livro digital, que, no lugar das páginas, possui blocos e ao invés de usar contas e partidas dobradas, ele usa endereços e saídas de transação encadeada. Para Diuliana (2014), a tecnologia foi desenvolvida e é a base da moeda digital Bitcoin. Um recurso para se registrar transações de forma que se garanta a sua integridade. Nesse contexto, o conteúdo do livro-caixa da organização tem origem a partir de dados confirmados por vários computadores em rede, de forma simultânea. Com a introdução desses dados, não podem mais ser alterados e estão disponíveis a todos os que fazem parte dessa rede.

Blockchains liberam a confiança, que está nas mãos de instituições centrais (tais como bancos, legisladores, financiadores, governos, grandes corporações), e permitem que elas se esvaiam desses velhos pontos de controle (MOUGAYAR, 2018). Assim sendo, para Rufino 2018), a partir da sua interpretação de Domenico Lerário, sócio da Econobit, consultoria de investimentos em Bitcoin, entende que a grande chave do blockchain é retirar o intermediário das transações e permitir que qualquer pessoa faça trocas voluntárias. Para Rufino (2018), a tecnologia utilizada para as transações em Bitcoin, é a grande inovação que viabiliza a redução da Burocracia e confere maior agilidade, confiabilidade, rastreabilidade e segurança das informações.

Ademais, tem as seguintes características: a) Integridade de dados e imutabilidade de transações, pois consiste em um registro que não pode ser alterado, revisado ou adulterado; b) Descentralização, já que não há a necessidade de um órgão intermediário que aprove a transação; e c) transparência e privacidade ao mesmo tempo, partindo do pressuposto que todos os dispositivos envolvidos nessa manipulação de um dado no blockchain tem acesso às ações desse dado. Em março de 2017, em uma entrevista publicada no seu site, Fernando Ulrich, entusiasta de 
moedas digitais e autor do livro "Bitcoin - a moeda na era digital", explica como acontece o processo dessa tecnologia: cada bloco contém $\mathrm{X}$ transações, e está ligado ao bloco anterior, formando assim uma "cadeia de blocos", chamado Blockchain (Ulrich, 2017).

Cada bloco desse dado contém uma identificação única chamada de "Hash", que é uma função matemática que pega uma sequência de letras e números aleatórios, gerando um código, como por exemplo: "a0680c04c4eb53884be77b4e10677f2b", chamado também como resumo da mensagem. Para o estudo de Marques (2017), o valor hash do bloco anterior deve ser acionado para o cálculo do valor de hash do bloco atual. A partir disso, torna-se possível criar uma conexão entre ambos os blocos. Deve-se ressaltar, ainda, que é fácil o processo de cálculo do valor de um hash, porém, não é possível descobrir a entrada desse código por se tratar de um sistema distribuído, ou seja, se alguém tentar alterar a quantidade de bitcoins, automaticamente, o hash seria modificado, possibilitando, então, a detecção da alteração.

\subsubsection{O BITCOIN}

De acordo com Souza (2014), há variados tipos de criptomoedas que circulam no mundo todo. Como exemplo, cita o Litecoin, o Peercoin e o Feathercoin. Reconhece, ainda, que existem outras, porém, frisa que a mais comum e conhecida é o Bitcoin. A pesquisa de Ulrich (2014), por sua vez, identificou que o pouco que se sabe sobre a origem do Bitcoin, ou seja, sobre quem o criou, é que esse possível criador atendia pelo pseudônimo de Satoshi Nakamoto. Sabe-se, também, que a criação da moeda teve o seu fim em 2008 e que a sua primeira operação foi feita no ano de 2009. A operação se tratou de uma simples transferência. Ulrich (2014), aponta, também, que o Bitcoin independe de uma autoridade central para fornecer os dados. É o principal atrativo da criptomoeda, pois pode fazer o mesmo que a moeda física, sendo o diferencial a sua atuação descentralizada.

Ulrich (2014), alude, ainda, que as características do Bitcoin são melhores do que as do dinheiro físico, pois a criptomoeda é escassa, divisível, portátil e caminha em 
direção do ideal monetário, pois, ao mesmo tempo, é "sem peso e sem espaço", ou seja, é incorpórea. Isso torna viável a transferência de propriedade a um custo, virtualmente, inexistente bem como não depende de um intermediário para a realização dessas transações. Contorna, então, todo o sistema bancário, pois ele está sujeito a intervenções governamentais. Ulrich (2014), elucida, também, que a criptomoeda é capaz de restaurar a solidez e o universalismo do padrão-ouro do mundo antigo assim como é capaz de aprimorar essa moeda, sendo vedado, ao governo, o controle desta. Essas moedas apenas existem no mundo virtual. Seus arquivos são digitais e são armazenados em "carteiras digitais" a partir de um celular ou computador.

As transações são verificadas, e o gasto duplo é prevenido, por meio de um uso inteligente de criptografia de chave pública. Tal mecanismo exige que a cada usuário sejam atribuídas duas "chaves", uma privada, que é mantida em segredo, como uma senha, e outra pública, que pode ser compartilhada com todos. Quando Maria decide transferir bitcoins ao João, ela cria mensagem, chamada de "transação", que contém a chave pública do João, assinando com sua chave privada. Achando a chave pública da Maria, qualquer um pode verificar que a transação foi de fato assinada com sua chave privada, sendo, assim, uma troca autêntica, e que o João é o novo proprietário dos fundos. A transação- e, portanto, uma transferência de propriedade dos bitcoins- é registada, carimbada com data e hora e exposta em um "bloco" do blockchain (o grande banco de dados, ou livro-razão da rede Bitcoin). A criptografia de chave pública garante que todos os computadores na rede tenham um registro constantemente atualizado e verificado de todas as transações dentro da rede Bitcoin, o que impede o gasto duplo e qualquer tipo de fraude (ULRICH, 2014, pp. 18-19).

Para Surda (2012) o maior empecilho quando se trata de BTC é a sua liquidez, e embora existam empresas que aceite o BTC como forma de pagamento, ainda não são todos os países que têm o conhecimento, não podendo ser considerada como moeda, no entanto, está em vias de ser. O mesmo autor, elenca que para escolher uma moeda, deve-se observar três requisitos: liquidez, reserva de valor e custos de transação. É válido ressaltar que essas criptomoedas não devem ser confundidas com a moeda eletrônica respaldada pela Lei de № 12.865, de 9 de outubro de 2013. A moeda eletrônica, diferentemente do Bitcoin, é regulamentada por atos normativos 
que são editados pelo Banco Central do Brasil, de acordo com as exigências do Conselho Monetário Nacional.

A moeda eletrônica, para Bacen (2017), deve ser entendida como os recursos em reais armazenados em dispositivo ou sistema eletrônico que permitem ao usuário final efetuar transação de pagamento. É, dessa forma, um modo de se referir aos créditos denominados em reais. Assim sendo, Bacen (2017), frisa que as moedas virtuais não podem ser referenciadas em reais ou, ainda, conforme as características estabelecidas pelos governos. Nesse sentido, a Receita Federal brasileira classifica o Bitcoin como um criptoativo, ou seja, como uma representação do valor digital, e, assim, o seu preço pode ser expresso tanto em moeda soberana quanto na modalidade de moeda local ou estrangeira.

\subsubsection{O PROCESSO DE MINERAÇÃO}

A mineração é um sistema que opera de forma, intrinsecamente, consensual, e, dessa forma, seu objetivo é confirmar e incluir as transações no blockchain. Seu papel é, também, a proteção da neutralidade da rede, e, assim, torna viável a possibilidade de computadores diversos serem organizados e sincronizados, de forma harmônica, com o sistema. Todas as transações realizadas com Bitcoins são enfileiradas em uma corrente chamada "Blockchain", para que novos blocos sejam inseridos nessa corrente, um algoritmo que calcula hashes é utilizado (BITCOIN, 2017). Esta metodologia impossibilita que uma moeda seja gasta mais de uma vez, já que gerar uma nova corrente implicaria em recalcular todos os nodos já criados. O processo de adicionar transações na "Blockchain" é realizado por um minerador que é remunerado com Bitcoins toda a vez que encontra um novo nodo.

A mineração de Bitcoin consiste em processar um block header a fim de encontrar um hash único que verifique a transação. Como a única maneira de calcular este hash é a partir dos processos de tentar e errar, a geração do Bitcoin está relacionada ao gasto de um processamento computacional (SOARES, 2012). No Bitcoin, como não há uma entidade central, qualquer usuário pode baixar o Software, comprar o maquinário especializado e com um elevado gasto de energia elétrica, fazer as validações de 
Bitcoin. Esses usuários, chamados de mineradores, recebem como recompensa, novos Bitcoins. De cada minerador é exigido resolver um problema matemático complexo, para poder receber os bitcoins, o que leva em média 10 min para cada problema ser solucionado. Quando o minerador valida as transações, ele transmite as transações em um bloco, e todas as redes podem comprovar que essas transações são válidas (Ulrich,2017). É o que podemos verificar na figura abaixo:

Figura 1 - Validação de transações com bitcoin e adição ao blockchain

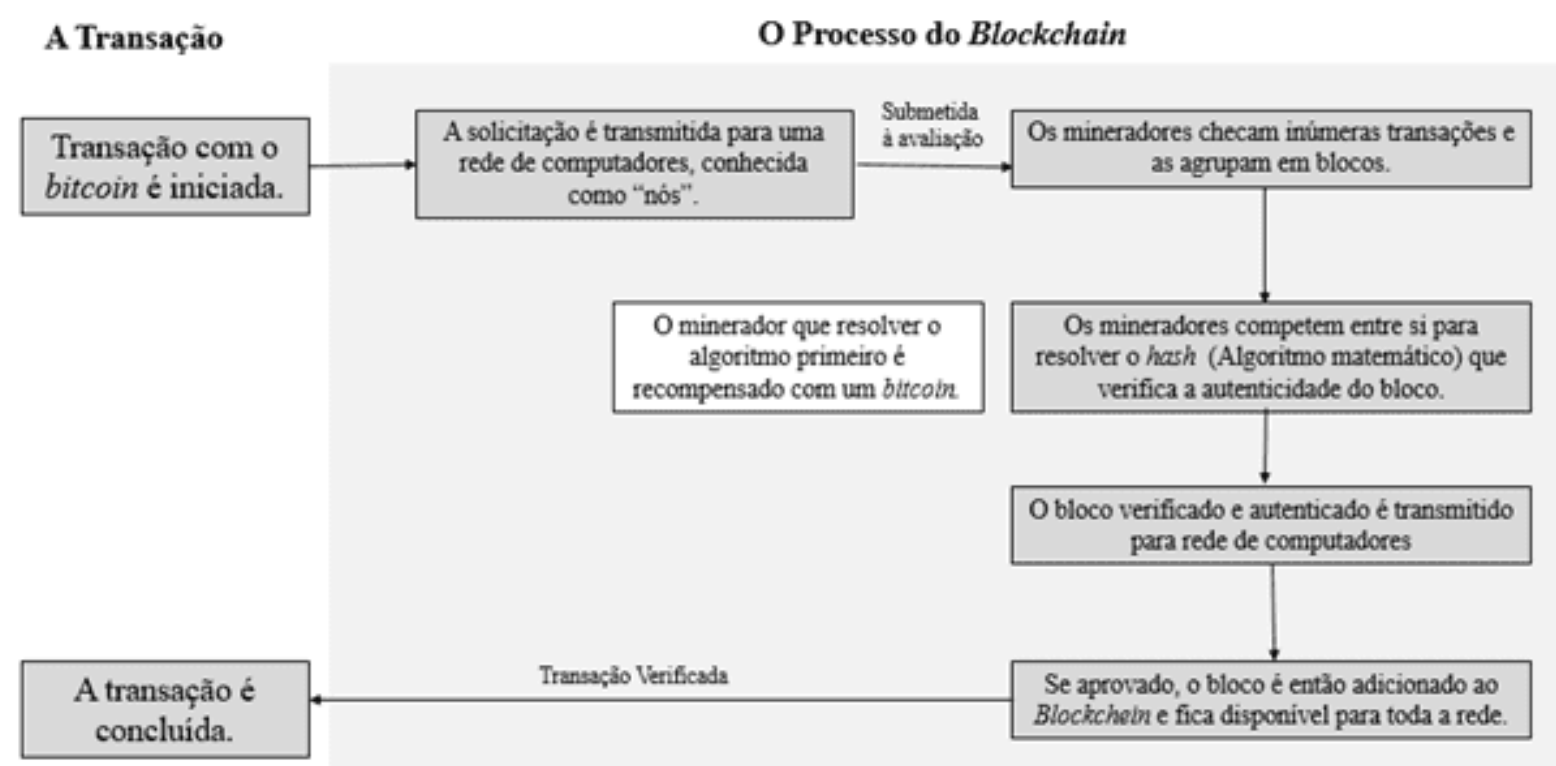

Fonte: Aswath Damodaran, 2017.

\subsection{LEGISLAÇÃO TRIBUTÁRIA BRASILEIRA}

\subsubsection{PRINCÍPIO DA CAPACIDADE CONTRIBUTIVA}

A pesquisa de Meirelles (1997) alude que a expressão "capacidade contributiva", desde a sua gênese, tem sido empregada como um sinônimo para os termos "riqueza" e/ou "patrimônio". Assim sendo, acaba evidenciando, desde a sua criação, as forças econômicas individuais que propiciavam o pagamento diversificado dos tributos. Essa carga tributária gerada seria, então, proporcional à riqueza bem como ao patrimônio, 
ambos acumulados. A Constituição Federal de 1988, a partir do inscrito no $\S 1^{\circ}$ do Art. 145, dispõe que:

Sempre que possível, os impostos terão caráter pessoal e serão graduados segundo a capacidade econômica do contribuinte, facultando à administração tributária, especialmente para conferir efetividade a esses objetivos, identificar, respeitados os direitos individuais e nos termos da lei, o patrimônio, os rendimentos e as atividades econômicas do contribuinte.

Conforme Carrazza (200), tal princípio hospeda-se nas dobras do princípio da igualdade e ajuda a realizar, no campo tributário, os ideais republicanos. Realmente, é justo e jurídico que, em termos econômicos, quem tem muito pague, proporcionalmente, mais impostos do que quem tem pouco. Quem tem maior riqueza deve, em termos proporcionais, pagar mais impostos do que tem menor riqueza. Noutras palavras, deve contribuir mais para a manutenção da coisa pública. Nesse contexto, é possível entender, segundo Menezes (2009), que esse princípio visa motivar a busca por uma sociedade mais justa e igualitária. Impõe, para tanto, uma tributação mais onerosa para os possuidores de uma maior concentração de riquezas. Assim, todos devem contribuir de forma proporcional aos recursos.

\subsubsection{A SONEGAÇÃO FISCAL}

A sonegação fiscal é um assunto que nos últimos anos tem sido muito discutido, sobretudo no Brasil, que tem enfrentado grande repercussão de práticas criminosas cometidas pelos entes do governo, dentre as quais estão a sonegação fiscal e a lavagem de dinheiro. A fim de melhor compreendê-la, eis o que a Lei № 4.729, de 14 de julho de 1965, define como crime de sonegação fiscal:

Art $1^{\circ}$ Constitui crime de sonegação fiscal:

I - prestar declaração falsa ou omitir, total ou parcialmente, informação que deva ser produzida a agentes das pessoas jurídicas de direito público interno, com a intenção de eximir-se, total ou parcialmente, do pagamento de tributos, taxas e quaisquer adicionais devidos por lei;

II - inserir elementos inexatos ou omitir, rendimentos ou operações de qualquer natureza em documentos ou livros exigidos pelas leis fiscais, 
com a intenção de exonerar-se do pagamento de tributos devidos à Fazenda Pública;

III - alterar faturas e quaisquer documentos relativos a operações mercantis com o propósito de fraudar a Fazenda Pública;

IV - fornecer ou emitir documentos graciosos ou alterar despesas, majorando-as, com o objetivo de obter dedução de tributos devidos à Fazenda Pública, sem prejuízo das sanções administrativas cabíveis;

$\mathrm{V}$ - Exigir, pagar ou receber, para si ou para o contribuinte beneficiário da paga, qualquer percentagem sobre a parcela dedutível ou deduzida do imposto sobre a renda como incentivo fiscal.

Em outras palavras, a Lei ํㅜ 4.729, de 1965, conforme Queiroz (2018), dispõe que aqueles que se apropriarem de meios ilícitos para desviar do pagamento de taxas, impostos ou tributos semelhantes bem como aqueles que prestarem declarações falsas ou se omitirem, de forma total ou parcial, com a intenção de se eximir do pagamento dessas tributos, comete, automaticamente, o crime de sonegação fiscal, cabível à punição correspondente. A sonegação fiscal reduz a capacidade do Estado de desenvolver as suas políticas públicas bem como impede ou retarda a prestação de serviços e ofertas de bens para entidades públicas tais como as escolas, hospitais assim como para a segurança e saneamento básico.

\subsubsection{PROPOSTA DE REGULAMENTAÇÃO DAS CORRETORAS DE CRIPTOMOEDAS (EXCHARGES)}

Carnut (2018) afirma, em seu estudo, que por volta de 2010, alguém acabou vendendo bitcoins em troca de dólares e outras moedas nacionais. É dessa forma que ganharam vida as famosas "casas de câmbio" ou "exchanges". Essas logo se tornaram a forma mais prática e barata pela qual os usuários podem obter bitcoins para realizar as suas trocas. A Receita Federal, objetivando criar uma normatização para as prestações de informações por parte das corretoras de valores (responsáveis por intermediar a compra e venda de criptoativos), realizou uma consulta pública que ficou conhecida como "RFB No 06/2018". Essa resolução permitiu a verificação da conformidade tributária bem como aumentou os insumos no combate da lavagem de dinheiro e da 
corrupção. Houve, ainda, um aumento da percepção de risco em relação aqueles contribuintes propícios à evasão fiscal.

Essa normatização prevê, ainda, a declaração por parte de pessoas físicas e jurídicas quando essas fazem uso de empresas no exterior, ou, ainda, quando não utilizam os ambientes disponíveis para as transações a partir das criptomoedas. A Receita Federal (2018) se preocupa, ainda, com a utilização das criptomoedas em operações de sonegação, lavagem e corrupção de dinheiro no país e fora dele. Defende, então, que a busca por aqueles que agem de forma anônima deve ser combatida, sobretudo por meio do acionamento da autoridade tributária para que se combate, de forma mais eficiente, práticas criminosas. O Portal do Bitcoin (2018) compartilha do mesmo ideal e, assim, alude que aqueles que descumprirem essa obrigação estarão sujeitos a multas de até 3\% da operação além da obrigação do Ministério Público Federal de tomar as devidas providências. $O$ atraso na entrega da declaração acarretará em uma multa de $\mathrm{R} \$ 500$ a $\mathrm{R} \$ 1.500,00$ ao mês.

\section{PROCEDIMENTOS METODOLÓGICOS DA PESQUISA}

Para este trabalho realizou-se uma pesquisa de caráter exploratório quanto aos seus objetivos, e bibliográfica quanto aos procedimentos técnicos. A população da pesquisa abrange todo material midiático ou documental que trata do tema Bitcoin, com foco em práticas de sonegação ou evasão fiscal. Desta população selecionamos uma amostra com os artigos mais atuais e completos que tratam do objeto da pesquisa, onde incluiu-se artigos, livros, sites, portais, revistas e publicações acerca do assunto das transações financeiras que envolvem a moeda virtual Bitcoin com intuito de constatar as possibilidades de sonegação fiscal. Tivemos como base o livro "Bitcoin: A moeda na era digital" de Fernando Ulrich (2014) para melhor compreender a natureza do bitcoin. Foram consultados artigos da Constituição Federal voltadas para o contribuinte e a Lei no ${ }^{\circ .729 / 65}$ que define o crime de sonegação fiscal.

Para verificar como são evidenciados nos registros contábeis as transações financeiras com criptomoedas, foi feito um levantamento de quais empresas aceitam bitcoin como forma de pagamento e dentre elas foram selecionadas as empresas que 
divulgam relatórios financeiros, dentre estas empresas, a Microsoft Corporation e a Dell, foram escolhidas devido a quantidade de informações financeiras publicada e a facilidade de encontrá-las em seus relatórios, a partir daí verificou-se se estes relatórios evidenciam as transações com bitcoin. No que tange a forma de contabilizar as movimentações com o Bitcoin, o presente trabalho não se propôs a estudar a fundo a forma que devem ser feitos os lançamentos e nem sugerir uma forma correta de fazê-lo, apenas buscou verificar se já existem parâmetros e/ou normas que indiquem como fazê-los.

Para isso, foram pesquisadas normas contábeis que tratam do assunto e após constatar que não existe nenhuma regulamentação específica para este ativo, foram feitas pesquisas em artigos, onde foram possíveis encontrar apenas simulações acerca dos lançamentos a serem feitos. A partir de documentos midiáticos foram levantadas informações nacionais e internacionais sobre crimes que usam a criptomoeda bitcoin como um meio de driblar as autoridades competentes. Dentre os crimes constatados estão a sonegação ou evasão fiscal e lavagem de dinheiro. Procurou-se, ainda, entender quais são as obrigações do contribuinte que realiza transações de compra e venda de criptomoedas perante a Receita Federal Brasileira (RFB) e para isso foram realizadas pesquisas no próprio site da RFB a fim de descobrir quais são as orientações voltadas para estes usuários e a partir disso verificar se as foram deixadas lacunas que abrem precedentes para a sonegação fiscal.

De posse das orientações dadas pela RFB, para elucidar a compreensão do leitor, foram realizadas simulações de ganho de capital sobre a alienação de bitcoin. Embora tenhamos conseguido atingir o objetivo, constatamos o quão difícil é cruzar informações de transações com bitcoin dos usuários. Pois, durante o estudo algumas linhas de pesquisa se tornaram inviáveis devido à dificuldade de encontrar os dados necessários. A princípio buscou-se obter informações no site da Receita Federal para verificar a quantidade de bitcoins que são declarados no Brasil para posteriormente obter dados de empresas que aceitam bitcoins ou das empresas que negociam bitcoin, as corretoras. Porém a pesquisa não foi possível uma vez que a falta de evidenciação das empresas que aceitam bitcoins como forma de pagamento e as 
informações das corretoras são em nível global, tornou-se impossível cruzar os dados com as informações das empresas Brasileiras.

\section{RESULTADOS E DISCUSSÕES}

\subsection{VERIFICAR OS REGISTROS CONTÁBEIS DA CRIPTOMOEDA, ESPECIFICAMENTE BITCOIN}

Os lançamentos fazem parte dos procedimentos contábeis internos de cada empresa, de modo que somente os relatórios e demonstrações são divulgadas, quando necessário, porém, a falta de normas regulamentares tem feito com que empresas que já aceitam pagamento via bitcoin, como a Dell e a Microsoft não evidenciem esse ativo, podendo colocá-lo apenas como um investimento sem informações complementares e nem notas explicativas. Isso dificulta o controle das autoridades competentes e não torna a informação contábil transparente, o que põe em jogo sua confiabilidade. Atualmente tem sido muito comum a aquisição de criptomoedas para fins especulativos, nesse caso, conforme (SILVA E CIA, 2018) ele deve ser reconhecido pelo valor de aquisição da seguinte forma:

D - Investimento em bitcoin

C - Banco

Os mesmos autores ainda fazem uma simulação voltada para as empresas corretoras de bitcoin, as excharges. Nesse caso, deverá reconhecer pelo valor de custo, da seguinte forma:

$D$ - Estoque de moedas virtuais

C - Banco

É válido ressaltar que embora os profissionais contábeis busquem registrar da maneira mais correta possível, a falta de regulamentação até o presente momento tem dificultado esse trabalho. Não há instrução, e o que se encontra são apenas 
simulações, como as citadas acima, de como se compreende a melhor forma de registrar essas transações.

\subsection{AVALIAÇÃO DO USO DO BITCOIN PARA PRÁtICAS CRIMINOSAS}

Ferrão (2018) elucida, em seu estudo, que o escopo principal que motivou a criação do Bitcoin se tratou da necessidade de facilitar a vida daqueles que, diariamente, realizam transações financeiras diversas bem como foi criado para fugir do controle dos governos sobre a moeda. Todavia, com a popularização do Bitcoin, a criptomoeda acabou caindo, também, nas mãos dos criminosos. Tanto aqueles que atacam no mundo virtual quanto no real possuem acesso aos bitcoins. Como exemplos de crimes a partir dos bitcoins, Garret (2017) cita os casos de sequestro (os criminosos têm exigido moedas virtuais em troca do resgate) e os crimes de ameaça (os criminosos passaram a extorquir as vítimas para obter bitcoins, e, para isso, ameaçam vazarem imagens íntimas, segredos de negócio, informações delicadas e semelhantes). Considera, ainda, os crimes de sonegação ou evasão fiscal como práticas criminosas.

A pouco tempo, registrou-se o primeiro caso de uso de bitcoins em operações investigadas pela "lava jato". Saraiva (2018) reitera que essa operação foi designada de "pão nosso". Teve como objetivo averiguar as irregularidades no Projeto PãoEscola. Esse projeto tinha como objetivo a ressocialização dos presidiários. Uma parcela expressiva do dinheiro desviado acabou sendo investida em bitcoin. $\mathrm{O}$ superintendente-adjunto da $7^{\text {a }}$ Região Fiscal da Receita Federal, Luiz Henrique Casemiro, afirmou que os responsáveis pela operação realizaram um teste para driblar os obstáculos projetados pelos órgãos públicos de controle financeiro. Segundo Ferrão (2018), um dos principais fatores que despertam a atenção dos criminosos é que eles acabam usufruindo dos benefícios que uma moeda descentralizada fornece. $O$ anonimato é um elemento que favorece as chantagens que acabam sendo pagas com o bitcoin. 


\subsection{DECLARAÇÃO DO IMPOSTO DE RENDA DE CRIPTOMOEDAS}

No programa do Imposto de Renda de Pessoa Física (IRPF), em "outros bens e direitos", as criptomoedas a partir do valor $\mathrm{R} \$ 1.000,00$ (mil reais), devem ser declaradas na Declaração de Ajuste Anual sob o código 99 - "Outros Bens e Direitos". No campo da "discriminação", deve descrever o máximo de informações possíveis, como: a quantidade de moedas que possui até o dia 31 de dezembro, a data de aquisição e de quem comprou, considerando o valor de aquisição. Além disso, as operações deverão ser apresentadas para a averiguação da verossimilidade via documentos hábeis e idôneos.

Se a soma das vendas de bitcoins não ultrapassar o valor $\mathrm{R} \$ 35$ mil no mês, o indivíduo fica isento do imposto de venda (Instrução Normativa SRF no 599/2005), precisa apenas registrar em "Rendimentos Isentos e Não Tributáveis" o ganho obtido. Agora se a soma das vendas de bitcoins exceder o valor $\mathrm{R} \$ 35.000,00$ (trinta e cinco mil reais) no mês, através do Programa de Apuração do ganho de Capital - GCAP, disponibilizado no site da RFB, a pessoa física deve declarar o valor de sua alienação, e pagará o imposto até o último dia do mês seguinte à data da venda, conforme Lei no 13.259/2016, art. 1ํ, descrito no quadro abaixo:

Quadro 1: Tributação dos Ganhos de Capital das Pessoas Físicas

\begin{tabular}{|l|l|}
\hline Alíquota & Ganho de capital a ser tributado \\
\hline $15 \%$ & De $R \$ 35$ mil a $R \$ 5$ milhões \\
\hline $17,5 \%$ & Acima de $R \$ 5$ milhões a $R \$ 10$ milhões \\
\hline $20 \%$ & Acima de $R \$ 10$ milhões a $R \$ 30$ milhões \\
\hline $22,5 \%$ & Acima de $R \$ 30$ milhões \\
\hline
\end{tabular}

Fonte: Planalto (2016)

Para melhor entendimento, vamos supor que o contribuinte comprou bitcoins no Valor de $R \$ 50.000,00$, e vendeu por $R \$ 60.000,00$. O Lucro será subtraído do valor de 
Corretagem e do valor de aquisição. Logo, o tributo que deve ser pago é o resultado da multiplicação de $15 \%$ sobre o lucro. Conforme ilustrado no quadro abaixo:

Quadro 2: Simulação do cálculo de imposto sob o ganho de capital com bitcoin

Valor de Alienação.

60.000

Custo da Corretagem.

560,70 )

Valor Líquido Alienação

$59.439,30$

Custo de Aquisição

$50.000,00)$

Ganho de Capital

$9.439,30$

\section{Alíquota}

\section{Imposto}

Devido.

Fonte: Elaborado pelas autoras (2019)

O que também poderia acontecer, que o valor da alienação de criptomoedas tivesse sido $R \$ 68.000,00$ (Sessenta e oito Mil reais), ao invés de $R \$ 60.000,00$, (sessenta mil reais) e como o usuário investiu em outras criptomoedas o Valor de $\mathrm{R} \$ 8.000,00$ (Oito Mil reais), o mesmo por ter sacado em espécie o valor de $\mathrm{R} \$ 60.000,00$ (sessenta mil reais), foi este o valor total declarado no mês para a Receita Federal. Levando em consideração que o contribuinte declarasse o valor total do ganho de capital $R \$ 68.000,00$ (Sessenta e oito Mil reais), e o valor de corretagem fosse o 
mesmo citado na simulação acima, pagaria de imposto o valor $R \$ 2.615,89$, (Dois mil e seiscentos e quinze, e oitenta e nove centavos) sendo uma diferença de $R \$ 1.200,00$ (mil e duzentos reais) do imposto que foi pago na situação anterior, considerando esta como uma forma de sonegação fiscal.

Em entrevista exclusiva para o Mercado Bitcoin, Mário Shingaki (2018), relata que quando se tratar de aquisições em euro ou em dólar adquirido no exterior, antes de declarar é preciso converter em reais. No caso das Pessoas Jurídicas, o Imposto de Renda é calculado com base no Lucro Real, Presumido ou Estimado. (GUIA DO BITCOIN, 2017). Segundo Shingaki (2018), em regra Geral é tributado em até 34\%, sendo 25 \% Imposto de renda mais uma contribuição social sobre o lucro líquido de 9 $\%$.

\subsection{OPINIÕES NACIONAIS E INTERNACIONAIS SOBRE O BITCOIN}

As operações via bitcoin têm despertado a atenção de governos diversos. Conteúdos sobre a temática se encontram disponíveis na Biblioteca do Congresso Americano. Nela, há o documento intitulado de "Regulation of Bitcoin in Selected Jurisdictions" (THE LAW LIBRABRY OF THE CONGRESS, 2014). Esse documento foi elaborado por analistas do governo americano a partir do estudo desses sobre a legislação de outras nações em relação a como elas dispunham sobre esse ativo financeiro. $O$ Internal Revenue Service (IRS) é um órgão que funciona como a Receita Federal brasileira. Ele afirma que as criptomoedas não devem ser compreendidas como uma entidade monetária voltada aos efeitos de tributação. Trata-se de uma mera propriedade, porém, o órgão reconhece que elas podem ser utilizadas como um meio de efetuação de pagamentos.

O Banco Central do Brasil, por meio do comunicado de № 31.379, de 16 de novembro de 2017, reitera que os bitcoins não são emitidos ou garantidos por qualquer autoridade monetária, e, dessa forma, não se pode resguardar a conversão dos bitcoins para moedas soberanas e essas tampouco serão lastreadas em ativos reais de qualquer espécie. Dessa forma, os detentores de bitcoins devem reconhecer o risco. Nessa perspectiva, o valor é atribuído conforme a confiança conferida pelos 
sujeitos ao seu emissor. As moedas virtuais (e outros instrumentos relacionados), segundo o Banco Central do Brasil (2017), implicam em transferências internacionais a partir de moedas estrangeiras que não se encontram isentas da obrigação de atendimento às normas de câmbio, em especial a realização de transações exclusivamente por meio de instituições autorizadas pelo Banco Central do Brasil a operar no mercado de câmbio.

Bill Gates, idealizador e criador da Microsoft, reitera que: "a principal característica de criptomoedas é seu anonimato. Não acho que seja algo positivo. É bom que um governo seja capaz de identificar lavagem de dinheiro, evasão fiscal e o financiamento do terrorismo" (BBC BRASIL, 2018). Nessa perspectiva, Theodoro (2018) alude que o infortúnio mais frequente ao fazer uso das criptomoedas, a partir de um viés tributário, propicia as operações de sonegação do ganho do capital, devido, sobretudo, ao anonimato. Mesmo com os problemas, esse ativo tem assumido uma representatividade bastante expressiva no mundo todo. Assim, segundo o Portal do Bitcoin (2018), tratar ele à revelia da Administração Pública, pode acarretar em prejuízos econômicos bem como pode-se favorecer e estimular o uso dos bitcoins para manter determinadas atividades fora dos olhos do Estado.

Conforme elucida Bastiani (2018), para que os crimes financeiros globais sejam combatidos, de forma efetiva, os líderes de fiscalizações de impostos criaram um grupo denominado de "Joint Chiefs da Global Tax Enforcement" (J5). O grupo conta com participantes da Austrália, dos Estados Unidos da América, da Holanda, do Canadá e do Reino Unido. O escopo principal dessa entidade é a redução da ameaça às administrações tributárias que é causada pelas criptomoedas e pela popularização do cibercrime. Bastiani (2018) reitera, ainda, que não existem dúvidas de que a falta de regulamentação dessas moedas virtuais viabiliza e, principalmente, populariza problemas como a sonegação bem como a evasão fiscal, devido à descentralidade da moeda. Favorece, também, outros tipos de fraude assim como os pagamentos de atividades ilícitas. 
Quadro 3 - Status dos países no combate à sonegação fiscal

\begin{tabular}{|c|c|c|}
\hline FONTE & PAÍS & STATUS \\
\hline $\begin{array}{l}\text { Portal } \\
\text { do } \\
\text { bitcoin } \\
\text { (2018) }\end{array}$ & Brasil & $\begin{array}{l}\text { A Receita Federal do Brasil passará a exigir que as } \\
\text { corretoras entreguem mensalmente uma declaração } \\
\text { com todas as operações de criptomoedas realizadas } \\
\text { pelos clientes, a fim de cruzar as informações de } \\
\text { posse de criptomoedas com as declarações } \\
\text { realizadas, e identificar as possíveis sonegações. }\end{array}$ \\
\hline $\begin{array}{l}\text { Studio } \\
\text { bitcoin } \\
\text { (2018) }\end{array}$ & Austrália & $\begin{array}{l}\text { Na Austrália, tem escritório de tributação australiano } \\
\text { investigando relatórios de possíveis evasões fiscais } \\
\text { usando com Bitcoin e moedas similares. }\end{array}$ \\
\hline $\begin{array}{l}\text { Thomson } \\
\text { Reuters } \\
\text { (2017) }\end{array}$ & Bolívia & $\begin{array}{l}\text { O governo boliviano proibiu o uso da bitcoin alegando } \\
\text { que ela propicia evasão fiscal e instabilidade } \\
\text { monetária. }\end{array}$ \\
\hline $\begin{array}{l}\text { Thomson } \\
\text { Reuters } \\
\text { (2017) }\end{array}$ & Bulgária & $\begin{array}{l}\text { A Agência de Receita Nacional do país emitiu novas } \\
\text { diretrizes de tributação, nas quais especifica que } \\
\text { qualquer receita gerada pela venda de moedas } \\
\text { digitais, como o bitcoin, será vista como receita da } \\
\text { venda de ativos financeiros, e tributada com uma taxa } \\
\text { de } 10 \% \text {. }\end{array}$ \\
\hline $\begin{array}{l}\text { Thomson } \\
\text { Reuters } \\
\text { (2017) }\end{array}$ & Canadá & $\begin{array}{l}\text { A fim de evitar a lavagem de dinheiro e o terrorismo, } \\
\text { tem a intenção de regularizar a criptomoeda. }\end{array}$ \\
\hline $\begin{array}{l}\text { Guia } \\
\text { do bitcoin } \\
\text { ( 2018) }\end{array}$ & China & $\begin{array}{l}\text { Bitcoins e criptos tem sérias restrições de circulação } \\
\text { no País e não são autorizados como forma de } \\
\text { pagamento. A gigante chinesa da internet, Tencent, } \\
\text { fez uma parceria com a autoridade fiscal da cidade de }\end{array}$ \\
\hline
\end{tabular}




\begin{tabular}{|c|c|c|}
\hline & & $\begin{array}{l}\text { Shenzhen para usar blockchain na luta contra a } \\
\text { evasão fiscal. }\end{array}$ \\
\hline $\begin{array}{l}\text { Veja } \\
\text { (2018) }\end{array}$ & $\begin{array}{l}\text { Coréia do } \\
\text { Sul }\end{array}$ & $\begin{array}{l}\text { A Coreia do Sul pretende proibir o uso de contas } \\
\text { bancárias anônimas em operações de criptomoedas, } \\
\text { a restrição tenta impedir que moedas virtuais sejam } \\
\text { usadas para lavagem de dinheiro e outros crimes. }\end{array}$ \\
\hline $\begin{array}{l}\text { Bitcoin move } \\
(2018)\end{array}$ & EUA & $\begin{array}{l}\text { O Internal Revenue Service (IRS), a agência tributária } \\
\text { federal dos EUA, considera a bitcoin e outras } \\
\text { criptomoedas como propriedade. Os investidores que } \\
\text { venderam ativos de criptomoeda, sendo ganho ou } \\
\text { perda de capital, precisam relatar essas transações } \\
\text { em um Formulário. A agência enfatiza:"Isso é } \\
\text { necessário para identificar e obter evidências sobre } \\
\text { indivíduos que usam bitcoin para lavar dinheiro ou } \\
\text { ocultar renda como parte de fraude fiscal ou outros } \\
\text { crimes federais". }\end{array}$ \\
\hline $\begin{array}{l}\text { Cointelegraph } \\
\text { (2018) }\end{array}$ & Japão & $\begin{array}{l}\text { Sob a legislação atual, as corretoras de criptomoedas } \\
\text { podem fornecer os dados dos clientes } \\
\text { voluntariamente, ou se recusar a fazê-lo. Mas o } \\
\text { Governo do Japão pretende elaborar um novo } \\
\text { sistema tributário no final de } 2019 \text {, a fim de evitar a } \\
\text { evasão fiscal em lucros significativos de transações } \\
\text { com criptomoedas. }\end{array}$ \\
\hline $\begin{array}{l}\text { Canaltech } \\
(2018)\end{array}$ & $\begin{array}{l}\text { União } \\
\text { Europeia }\end{array}$ & $\begin{array}{l}\text { O Parlamento Europeu quer acabar com o anonimato } \\
\text { envolvido em transações, câmbios e outros através } \\
\text { da regulamentação. São medidas voltadas na luta } \\
\text { contra crimes financeiros, lavagem de dinheiro, } \\
\text { evasão de divisas, sonegação fiscal e, acima de tudo, } \\
\text { combate contra o terrorismo. }\end{array}$ \\
\hline
\end{tabular}


Fonte: Elaborado pelas Autoras (2019)

\section{CONCLUSÃO}

Tendo em vista a relevância do mercado de criptomoedas no país, o presente trabalho teve como objetivo verificar de que forma as criptomoedas podem ser utilizadas como instrumento de sonegação fiscal através das transações financeiras de bitcoin e se isto é refletido nos registros contábeis. Na verificação dos registros contábeis das criptomoedas, especificamente o bitcoin, constatou-se ausência de informações satisfatórias relacionadas aos ganhos e investimentos com criptomoedas, pois as empresas que aceitam Bitcoin como forma de pagamento não evidenciam de forma clara e objetiva esse ativo, uma vez que os mesmos não constam nos seus relatórios contábeis e nem em notas explicativas. Paralelo a isso, os lançamentos contábeis de criptomoedas não são encontrados na literatura, de modo que só foram encontradas simulações de como devem ser feitos, logo, verificou-se que a falta de normas específicas permite que seus registros sejam feitos de forma subjetiva.

Essa nova forma de transação financeira, abre precedentes para práticas criminosas realizadas não só no mundo virtual, como também no mundo real, o bitcoin tem sido usado como moeda de troca em casos de sequestro, ameaça, e outros crimes. Também foi identificado sua utilização como meio de lavar dinheiro, conforme constatado na operação Pão Nosso da Lava Jato. Observou-se que as obrigações para a declaração de ajuste anual e ganho de capital de criptomoedas, não são suficientes para evitar a sonegação fiscal, uma vez que a RFB não consegue cruzar as informações da posse de criptomoedas das declarações feitas pelos usuários com as informações prestadas pelas corretoras. Além disso, existem os ganhos de capital de transações que não são realizados pelas corretoras, que dificulta ainda mais este controle, pois as declarações destes valores dependem somente da índole das partes envolvidas.

Concluímos ainda que outro meio de sonegação fiscal, é pelo envio de dinheiro via bitcoins para outros países. É possível que uma pessoa compre Bitcoins no Brasil, por exemplo, e solicite que sua corretora transfira os Bitcoins para uma conta em outro 
país a uma taxa incomparavelmente menor que a dos Bancos, e com uma burocracia ínfima. Esta falta de regulamentação, impede ainda que tributos de todas as esferas governamentais sejam recolhidos, qualificando o bitcoin, nesse sentido, como um instrumento de sonegação fiscal. Tendo atingido seu objetivo, o presente trabalho deixa sua contribuição à comunidade acadêmica e profissional da área, e ainda abre precedentes para novas pesquisas. Como sugestões para pesquisas futuras propõese que sejam realizadas simulações dos possíveis registros contábeis de transações financeiras com criptomoedas e que sejam analisadas as normas e obrigações tributárias dos países que possuem legislação de criptomoedas.

\section{REFERÊNCIAS}

ABNT - Associação Brasileira de Normas Técnicas. NBR 14724: Informação e documentação. Trabalhos Acadêmicos - Apresentação. Rio de Janeiro: ABNT, 2011.

AMERICO, F. Cidade Chinesa vai usar blockchain na luta contra a evasão fiscal. Guia do Bitcoin, 2018. Disponível em: https://guiadobitcoin.com.br/cidade-chinesa-vaiusar-blockchain-na-luta-contra-a-evasao-fiscal/. Acesso em: 11 jan. 2019.

BANCO CENTRAL DO BRASIL (BACEN). BC esclarece sobre os riscos decorrentes da aquisição das chamadas "moedas virtuais" ou "moedas criptografadas". Brasília, 2014. Disponível em: https://www.bcb.gov.br/ptbr/\#!/c/notas/14946. Acesso em: 14 Ago 2018.

BASTIANI, A. Autoridades globais juntam-se para combater a evasão fiscal possibilitada pelas criptomoedas. Criptomoedas Facil, 2018. Disponível em: https://www.criptomoedasfacil.com/autoridades-globais-juntam-se-para-combater-aevasao-fiscal-possibilitada-pelas-criptomoedas/. Acesso em: 16 jan. 2019.

BERMAN, A. Governo japonês vai impedir a evasão do imposto de cripto com novo sistema de relatórios, dizem fontes. Cointelegraph, 2018. Disponível em: https://br.cointelegraph.com/news/crypto-exchange-quadrigacx-missing-145-mlnafter-death-of-founder. Acesso em: 22 dez. 2018. 
BITCOIN, S. Escritório de tributação da Austrália quer evitar a evasão fiscal relacionada ao Bitcoin; Studio Bitcoin. 2018. Disponível em: https://studiobitcoin.com/escritorio-de-tributacao-da-australia-quer-evitar-a-evasaofiscal-relacionada-ao-bitcoin/. Acesso em: 22 dez. 2018.

BRASIL, BBC. As razões de Bill Gates para dizer que as criptomoedas "matam". 2018. Disponível em: https://www.bbc.com/portuguese/geral-43257362. Acesso em: 15 jan. 2019.

BRASIL, LEI № 13.259, DE 16 DE MARÇO DE 2016. Altera as Leis nos 8.981, de 20 de janeiro de 1995, para dispor acerca da incidência de imposto sobre a renda na hipótese de ganho de capital em decorrência da alienação de bens e direitos de qualquer natureza, e 12.973, de 13 de maio de 2014, para possibilitar opção de tributação de empresas coligadas no exterior na forma de empresas controladas; e regulamenta o inciso XI do art. 156 da Lei no 5.172, de 25 de outubro de 1966. Código Tributário Nacional, Brasília, DF, 16 Mar. 2016. Disponível em: http://www.planalto.gov.br/ccivil_03/_Ato2015-2018/2016/Lei/L13259.htm. Acesso em: 31 jan 2019.

BRASIL, LEI № 4.729, DE 14 DE JULHO DE 1965. Define o crime de sonegação fiscal e dá outras providências, Brasília, DF, 14 de jul. 1965, 144º da Independência e 77ํ da República. Disponível em: http://www.planalto.gov.br/ccivil_03/LEIS/19501969/L4729.htm. Acesso em: 31 jan.2019.

BRASIL AGÊNCIA. Receita está de olho em transações de moedas virtuais. 2018. Disponível em: https://dcomercio.com.br/categoria/leis-e-tributos/receita-esta-deolho-em-transacoes-de-moedas-virtuais. Acesso em: 09 jan. 2019.

CANALTECH. União Europeia quer acabar com o anonimato em transações com criptomoedas. 2018. Disponível em: https://www.coindesk.com/germany-considerscrypto-legal-equivalent-to-fiat-for-tax-purposes. Acesso em: 17 jan.2019.

CARRAZZA, R. A. Curso de direito constitucional tributário. 5. Ed. São Paulo: Malheiros, 1993. 
DINIZ, E. O blockchain veio para ficar. GV-executivo, v. 17, n. 3, p. 51, 2018.

DO BRASIL, C. F. Constituição federal. São Paulo: Revista dos Tribunais, 1988.

FARINI, R. Evasão Fiscal. BITCOIN MOVE. - 15/04/2018. Disponível em: https://www.bitcoinmove.com.br/evasaofiscal/ . Acesso em: 16 jan.2019.

FERRÃO, R. Cinco pontos sensíveis no uso de bitcoin para práticas criminosas. Conjur, 2018. Disponível em https://www.conjur.com.br/2018-abr-04/rubia-ferraocinco-pontos-sensiveis-uso-bitcoins-crimes. Acesso em: 20 dez. 2018.

GUSSON, C. G20: Conheça o status do Bitcoin em cada País integrante do grupo. Criptomoedas Fácil, 2018. Disponível em: https://www.criptomoedasfacil.com/g20-conheca-o-status-do-bitcoin-em-cada-paisintegrante-do-grupo/. Acesso em: 13 dez. 2018.

MARQUES, D. Se você entender a função da hash, você entenderá da blockchain. Guia do Bitcoin, 2017. Disponivel em: https://guiadobitcoin.com.br/sevoce-entender-a-funcao-da-hash-voce-entendera-a-blockchain/ . Acesso em: $20 \mathrm{dez}$. 2018.

MEIRELLES, J. R. O princípio da capacidade contributiva. Brasília a. 34 n. 136 out./dez. 1997.

MENEZES, F. K. de. M. Justiça tributária: questão de cidadania: o princípio da capacidade contributiva. Âmbito Jurídico, Rio Grande, v. 12, n. 68, 2009.

MOUGAYAR, W. Blockchain para negócios: promessa, prática e aplicação da nova tecnologia da internet. Rio de Janeiro: Alta Books Editora, 2018.

QUEIROZ, M. V. Índia notifica milhares de contribuintes que investiram em criptomoedas: no Brasil, as moedas devem ser declaradas como bens, e os ganhos são tributados. ANTIDOPA, 2018. Disponível em: http://antipoda.com.br/india-imposto-criptomoedas/. Acesso em: 16 jan. 2019. 
REUTERS, T. Como o mundo está lidando com as moedas digitais. 2017. Disponível em: https://www.thomsonreuters.com.br/pt/financeiras/blog/como-omundo-esta-lidando-com-as-moedas-digitais.html. Acesso em: 10 dez. 2018

RFB - Receita Federal do Brasil. A Sonegação Fiscal e a Corrupção. 2017. Disponível em: http://receita.economia.gov.br/dados/receitadata/arrecadacao/relatorios-doresultado-da-arrecadacao. Acesso em: 31 jan 2019.

RFB - Receita Federal do Brasil. Instrução Normativa Secretaria da Receita Federal № 599, DE 28 DE DEZEMBRO DE 2005. Dispõe sobre os arts. 38, 39 e 40 da Lei no 11.196, de 21 de novembro de 2005, relativamente ao Imposto de Renda incidente sobre ganhos de capital das pessoas físicas. Diário Oficial da República Federativa do Brasil, Brasília, 2005.

RIGGS, W. Receita Federal do Brasil pede que corretoras de criptomoedas declarem operações de clientes. PORTAL DO BITCOIN, 2018. Disponível em: https://portaldobitcoin.com/receita-federal-do-brasil-pede-que-corretoras-decriptomoedas-declarem-operacoes-de-clientes/. Acesso em: 07 jan. 2019.

ROCHA, D. et al. Blockchain e a Integridade de Dados na Validação de Sistemas Computadorizados. Disponível em: https://fiveconsultoria.com/blockchain-e-aintegridade-de-dados-na-validacao-de-sistemas-computadorizados/. Acesso em: 13 jan. 2019.

RUFINO, I. O que é, afinal, Blockchain? Diário do Comércio, 2018. Disponível em: https://dcomercio.com.br/categoria/inovacao/glossario-do-empreendedor-o-que-eafinal-blockchain. Acesso em: 05 jan. 2019.

SANTANA, E. Você sabia que deve declarar os bitcoins à receita? Política Estadão, 2018. Disponível em: https://politica.estadao.com.br/blogs/faustomacedo/voce-sabia-que-deve-declarar-os-bitcoins-a-receita/. Acesso em: 13 jan. 2019 
SARAIVA, J. Criminosos usam bitcoin em esquema de lavagem. 2018. Disponível em:

https://www.correiobraziliense.com.br/app/noticia/politica/2018/03/13/interna_politica, 665758/criminosos-usaram-bitcoin-em-esquema-de-lavagem-diz-lava-jato.shtml. Acesso em: 18 jan.2019.

SHINGAKI, M. Como declarar bitcoins. Mercado Bitcoin, 2018. Disponível em: https://www.youtube.com/watch?v=b8eagVlxrqs\&t=1819s. Acesso em: 05 jan. 2019.

SILVA, D. R. da; CIA, J. N. de. S. Bitcoin: reconhecimento, mensuração e contabilização da moeda digital. In: Moving accounting forward, 2018.

SOARES, F. A. Construindo um Minerador Bitcoin em FPGAs. 2012.

SOUZA, R. de. Além dos bitcoins: conheça outras moedas virtuais. Disponível em: http://www.tecmundo.com.br/bitcoin/46659-alem-dos-bitcoins-conheca-outrasmoedas-virtuais.htm. Acessado em: 03 de Set de 2018.

SPUTNIKNEWS. Criptomoedas são uma forma de driblar o fisco brasileiro? 2018. Disponível em: https://br.sputniknews.com/economia/2018111912715216moedas-virtuais-brasil/. Acesso em: 11 jan. 2019

SURDA, P. Economics of Bitcoin: is Bitcoin an alternative to fiat currencies and gold? Diploma Thesis, Wirtschaftsuniversitätx' Wien, 2012. Disponível em: http://dev.economicsofbitcoin.com/mastersthesis/mastersthesis-surda-2012-1119b.pdf. 2014. Acesso em: 20 Ago 2018.

THE LAW LIBRABRY OF THE CONGRESS. Regulation of Bitcoin in Selected Jurisdictions. Washigton, 15 de Janeiro de 2014. Disponível em: www.loc.gov/law/help/bitcoin-survey/regulation-of-bitcoin.pdf. Acessado em: 05 de Setembro de 2018.

THEODORO, T. Criptomoedas dão oportunidades de sonegação. Portal do Bitcoin, 2018. Disponível em: https://portaldobitcoin.com/criptomoedas-dao- 
oportunidades-de-sonegacao-diz-advogado-brasileiro-em-artigo/. Acesso em: 11 jan. 2019.

ULRICH, F. O blockchain é incorruptível. Youtube, 2017. Disponivel em: https://www.youtube.com/watch?v=H9b8c0DxSSE. Acesso em: 04 Janeiro 2019.

ULRICH, F. Como funciona o bitcoin: a mineração. Youtube, 2017. Disponivel em: https://www.youtube.com/watch?v=jUbOryzg-yM . Acesso em: 04 Janeiro 2019.

ULRICH, F. Bitcoin: a moeda na era digital. São Paulo: LVM Editora, 2017.

UMPIERES, R. T. Como declarar bitcoin e outras criptomoedas no imposto de renda. Infomoney, 2018.2 Disponível em: https://www.infomoney.com.br/mercados/bitcoin/noticia/7283840/como-declararbitcoin-e-outras-criptomoedas-no-imposto-de-renda. Acesso em: 03 jan. 2019.

VEJA. Coreia do Sul proíbe negócios com bitcoin com contas anônimas. 2018. Disponível em: https://veja.abril.com.br/economia/coreia-do-sul-proibe-negocios-combitcoin-com-contas-anonimas/. Acesso em: 15 jan.2019.

VEJA. IR 2018: Como declarar bitcoins e outras criptomoedas. 2018. Disponível em: https://veja.abril.com.br/tveja/em-pauta/ir-2018-como-declarar-bitcoins-e-outrascriptomoedas/. Acesso em: 04 jan. 2019.

Enviado: Setembro, 2019.

Aprovado: Outubro, 2019. 